\title{
Biochemical and clinical evidence that aspirin-intolerant asthmatic subjects tolerate the cyclooxygenase 2-selective analgetic drug celecoxib
}

\author{
Pär Gyllfors, MD,a Grazyna Bochenek, MD,b John Overholt, MD,c \\ Diane Drupka, BSc, ${ }^{d}$ Maria Kumlin, BM, PhD, e James Sheller, MD, PhD,c \\ Ewa Nizankowska, MD, PhD,b Peter C. Isakson, PhD,d Filip Mejza, MD,b \\ James B. Lefkowith, MD,d Sven-Erik Dahlén, MD, PhD,e Andrew Szczeklik, MD, \\ PhD, bohn J. Murray, MD, PhD,c and Barbro Dahlén, MD, PhDf Stockholm, Sweden, \\ Krakow, Poland, Nashville, Tenn, and Chicago, Ill
}

\begin{abstract}
Background: Subjects with aspirin-intolerant asthma (AIA) respond with bronchoconstriction and extrapulmonary adverse reactions to conventional nonsteroidal anti-inflammatory drugs (NSAIDs) that inhibit the cyclooxygenase (COX) step in the biosynthesis of prostaglandins. Recently, 2 isotypes of COX have been identified, and COX-2-selective NSAIDs have been developed for treatment of inflammatory disorders. Objective: We investigated whether 33 subjects with a typical history of AIA tolerated the new COX-2-selective NSAID celecoxib.

Methods: All subjects displayed current aspirin sensitivity in oral or inhalation challenge tests. The subjects first underwent a double-blind, randomized, cross-over, increasing-dose challenge with placebo or celecoxib $(10,30$, or $100 \mathrm{mg}$ in suspension) on 2 occasions 7 days apart. Thereafter, all subjects were exposed to $400 \mathrm{mg}$ of celecoxib administered during an open challenge session as two 200-mg doses 2 hours apart. Lung function, clinical symptoms, and urinary excretion of leukotriene $\mathbf{E}_{4}\left(\mathrm{LTE}_{4}\right)$ were monitored, with the latter being a sensitive biochemical marker of aspirin intolerance.

Results: There were no changes in lung function or extrapulmonary symptoms during the double-blind sessions or in urinary excretion of $\mathrm{LTE}_{4}$. Also, the highest recommended daily dose of celecoxib was well tolerated, with no symptoms, lung
\end{abstract}

From athe Division of Respiratory Medicine, Department of Medicine at Karolinska Hospital, Karolinska Institutet, Stockholm; bthe Department of Medicine, The Jagellonian University, Krakow; cthe Department of Medicine and Pharmacology, Vanderbilt University Medical Center, Nashville; dPharmacia Corp, Chicago; experimental Asthma and Allergy Research, The National Institute of Environmental Medicine, Karolinska Institutet, Stockholm; and fthe Division of Respiratory Medicine, Department of Medicine at Huddinge University Hospital, Karolinska Institutet, Stockholm. Drs Gyllfors and Bochenek contributed equally.

Supported by an operating grant from Pharmacia Corp and infrastructure research support from The Swedish Heart Lung Foundation, The Swedish Medical Research Council (project 71X-9071), the Foundation for Health Care Sciences and Allergy Research, and National Institutes of Health grant GM15431.

Received for publication December 18, 2002; revised February 6, 2003; accepted for publication February 7, 2003

Reprint requests: Sven-Erik Dahlén, MD, PhD, Experimental Asthma and Allergy Research, The National Institute of Environmental Medicine, Karolinska Institutet, SE-171 77, Stockholm, Sweden.

C) 2003 Mosby, Inc. All rights reserved.

$0091-6749 / 2003 \$ 30.00+0$

doi:10.1067/mai.2003.1450 function changes, or alterations in urinary $\mathrm{LTE}_{4}$ levels. Conclusions: A group of subjects with clinically well-documented AIA tolerated acute challenge with the selective COX2 inhibitor celecoxib. The findings indicate that the intolerance reaction in AIA is due to inhibition of COX-1. Large long-term studies of COX-2 inhibitors in AIA should be undertaken. (J Allergy Clin Immunol 2003;111:1116-21.)

Key words: Aspirin intolerance, asthma, nonsteroidal anti-inflammatory drugs, cyclooxygenase inhibition, $\mathrm{COX}-2$

Ingestion of aspirin and related nonsteroidal antiinflammatory drugs (NSAIDs) precipitates severe bronchoconstriction in a proportion of subjects with asthma. In some cases the reactions are very strong and generalized, and fatal cases regrettably occur when patients inadvertently are prescribed antiflogistic remedies or obtain pain killers over the counter. The patients have a typical clinical picture with asthma, recurrent rhinosinuitis, and/or nasal polyposis, as well as the peculiar intolerance to the vast majority of aspirin-like drugs (NSAIDs). ${ }^{1}$ Therefore the syndrome is named aspirinintolerant asthma (AIA).

There is a strong body of evidence supporting the hypothesis that the cyclooxygenase (COX) enzyme has a pivotal role in the initiation of the intolerance reaction. ${ }^{1}$ COX catalyzes the formation of prostaglandins (PGs) and thromboxane (TX), and common NSAIDs inhibit COX and thereby the formation of PGs and TX. Moreover, the propensity of different NSAIDs to evoke aspirin-induced bronchoconstriction in aspirin-intolerant individuals was found to correlate directly with their potency as COX inhibitors. ${ }^{2}$ The dramatic effect of COX inhibitors in these particular patients is believed to be related to an abnormal dependency on the anti-inflammatory action of $\mathrm{PGE}_{2}, 1,3,4$ resulting in mast cell activation on removal of endogenous $\mathrm{PGE}_{2}$ by $\mathrm{COX}$ inhibitors. However, along with many other aspects of this intriguing syndrome, the mechanism is not conclusively proved.

Recently, 2 isoforms of COX have been identified and named COX-1 and COX-2.5 COX-1 is generally constitutively expressed in many cells in which PGs have physiologic functions (eg, formation of $\mathrm{TXA}_{2}$ in platelets or 


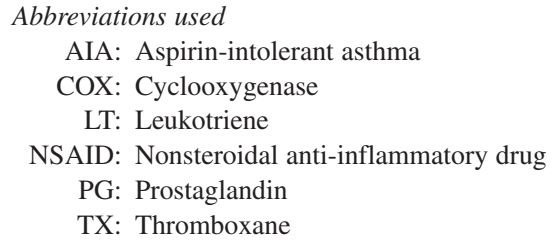

synthesis of cytoprotective PGs in the gastric mucosa). In contrast, COX-2 is, with some exceptions, generally not found in healthy tissues, but its expression is markedly induced in inflammation. Because the pharmacology of the 2 enzymes differ, it has been possible to introduce a new class of drugs with COX-2 selectivity for treatment of inflammatory disorders and, in particular, arthritis. ${ }^{5}$ The 2 first COX-2 inhibitors to be approved for use, celecoxib and rofecoxib, have been found to be as effective in the treatment of several inflammatory disorders as the COX-unselective common NSAIDs. ${ }^{6,7}$ This clinical efficacy has been documented to be associated with significantly less gastrointestinal bleeding, $, 8,9$ the most common and serious side effect of conventional NSAIDs, which is alone the major cause of death as a result of drug-induced adverse reactions. 10

The obvious question has then arisen of whether patients with AIA can use COX-2 inhibitors. The observation that salicylic acid, which is relatively COX-2 selective, ${ }^{11}$ generally is tolerated by patients with AIA ${ }^{12}$ would support the hypothesis that they tolerate COX-2 inhibition. There have also been reports that NSAIDs, such as nimesulide or meloxicam, with larger relative COX-2 inhibitory profiles in ex vivo testing have been tolerated by a proportion of aspirin-intolerant patients, but the evidence has not been unequivocal. ${ }^{13-15}$ For the understanding of the mechanisms in AIA, it has therefore become important to establish whether truly COX-2-selective drugs can be tolerated by patients with AIA. Obviously, for the patients, this would be a great benefit because they currently are restricted primarily to the use of weaker NSAIDs, such as acetaminophen, or unnecessarily strong treatments, such as glucocorticosteroids or morphine-like drugs, for the treatment of inflammation or pain.

On the basis of these considerations, we hypothesized that the newer and more potent COX-2 inhibitors would be tolerated by patients with AIA. We therefore conducted a study in which subjects with documented AIA were challenged orally with celecoxib. Because aspirin-intolerant individuals might experience extrapulmonary symptoms in addition to bronchoconstriction, the study protocol included monitoring of vital signs, nasal symptoms, conjunctivitis, urticaria, and skin rashes, as well as gastrointestinal symptoms. We have previously reported part of the initial findings in a subset of the subjects. ${ }^{16}$ The present communication contains all data from the 33 subjects who completed the investigation. In addition to comprehensive clinical recordings, urinary excretion of leukotriene $\mathrm{E}_{4}\left(\mathrm{LTE}_{4}\right)$ was used as a sensitive biochemi- cal marker of the intolerance reaction because it is established that urinary $\mathrm{LTE}_{4}$ increases during aspirin-induced intolerance reactions. ${ }^{17,18}$

\section{METHODS}

\section{Subjects}

Thirty-three subjects (Table I) with asthma and aspirin intolerance were recruited from the University Hospitals in Stockholm (n $=12)$, Krakow $(\mathrm{n}=11)$, and Nashville $(\mathrm{n}=10)$. Their asthma was stable, with no exacerbations and change in steroid dose during the past 3 months and 6 weeks, respectively. For inclusion, a positive response (Table II) to challenge with inhaled ${ }^{19}$ or oral ${ }^{20}$ aspirin was required within 9 months before the study. Subjects with sulfonamide allergy were excluded. None of the subjects had tried COX2 inhibitors before the study.

\section{Study design}

The study was approved by the respective ethical review boards and drug regulatory authorities, and the subjects provided signed informed consent. After a screening visit that included aspirin challenge if this had not been done within 9 months, each subject completed 3 study days $7 \pm 2$ days apart. The first 2 days involved a double-blind, randomized, 2-period, cross-over oral challenge with increasing doses of celecoxib $(10,30$, and $100 \mathrm{mg}$ ) and placebo. The third study day was an open-label challenge with two 200-mg doses of celecoxib.

\section{Study day procedures}

The challenges always started in the morning, and baseline pulmonary function, measured as $\mathrm{FEV}_{1}$, was required to be $70 \%$ or greater of predicted value. Leukotriene receptor antagonists and cromones had been withheld for 2 days, long-acting $\square$-agonists for 3 days, and short-acting $\square$-agonists for 6 hours. Celecoxib or placebo were administered at 2-hour intervals under direct supervision of study personnel. Spirometry and vital signs were followed at $15-$ to 30-minute intervals after each dose. Nasal symptom scores (0-3) and signs of conjunctivitis, dermal flush, gastrointestinal symptoms, or urticaria-angioedema were assessed at baseline and at 1 and 2 hours after each dose.

\section{Drugs}

Celecoxib (Celebrex) and its placebo were provided by Pharmacia Corp (Chicago, Ill) in coded bottles. The study drug (free base) and the placebo formulation were suspended in a concentrated Tween 80-ethanol solution by using a sonicator and diluted in 80 $\mathrm{mL}$ of apple juice. For the open-label challenge, the first dose was given as a $200-\mathrm{mg}$ oral suspension followed 2 hours later by intake of the commercially available $200-\mathrm{mg}$ capsule.

\section{Urinary $\mathrm{LTE}_{\mathbf{4}}$}

On each study day, urine samples for measurement of $\mathrm{LTE}_{4}$ were obtained before dosing (baseline) and hourly thereafter. The concentration of $\mathrm{LTE}_{4}$ was determined by using a previously validated enzyme immunoassay method. ${ }^{21}$ During a majority of the screening aspirin challenges, urine was collected before and after (0-6 hours) the reactions. This confirmed a highly significant $(P<.001$, paired Student $t$ test) and, on average, 4-fold peak increase in the urinary excretion of $\mathrm{LTE}_{4}$ after a positive intolerance reaction (Fig 1).

\section{Statistics}

On the basis of several conservative estimations, the study was designed to have a power of at least $74 \%$ to detect true responders to celecoxib in 30 completed subjects. The study results, however, 


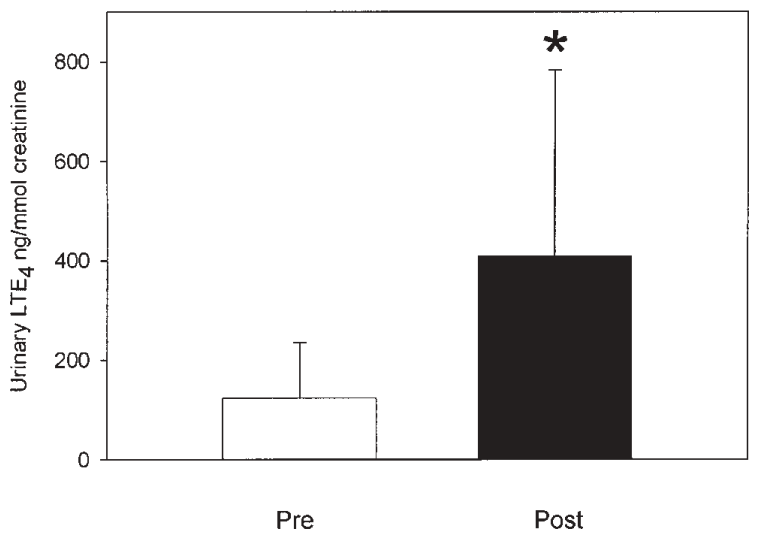

FIG 1. Urinary excretion of $\mathrm{LTE}_{4}$ (mean $\pm \mathrm{SD}$ ) before and after positive screening challenge with aspirin in 19 of the subjects participating in the study. The postchallenge value represents the peak excretion within 2 hours after the final dose of aspirin. The postchallenge (Post) value is highly significantly different from the prechallenge (Pre) value $(P<.001$, Student paired $t$ test).

made statistical analysis of the proportion of responders unnecessary. Group means \pm SD have been calculated for the variables presented in the figures to display data.

\section{RESULTS}

\section{Airway responses}

There were no significant bronchoconstrictor responses after placebo or active drug administration during the double-blind phase (Fig 2, A). Therefore all patients were subjected to the open-label challenge with two 200-mg doses of celecoxib. This provocation was also well tolerated by all patients, with no significant changes in pulmonary function (Fig 2, B).

\section{Nasal responses}

There were no changes in nasal symptom scores during the double-blind or the open-label challenge sessions (Fig 3).

\section{Other extrapulmonary responses}

There were no signs of dermal flush, urticaria, or gastrointestinal symptoms after any of the celecoxib sessions. One subject displayed slight conjunctivis symptoms after placebo and another after celecoxib. None of the subjects was judged as having symptoms caused by the study medication.

\section{Urinary $\mathrm{LTE}_{\mathbf{4}}$}

There was no change in urinary $\mathrm{LTE}_{4}$ levels during the sessions when celecoxib was administered (Fig 4).

\section{DISCUSSION}

In this study of 33 patients with asthma and documented aspirin intolerance, all subjects tolerated the selective COX-2 inhibitor celecoxib. Although celecoxib was administered in increasing doses up to twice the normal
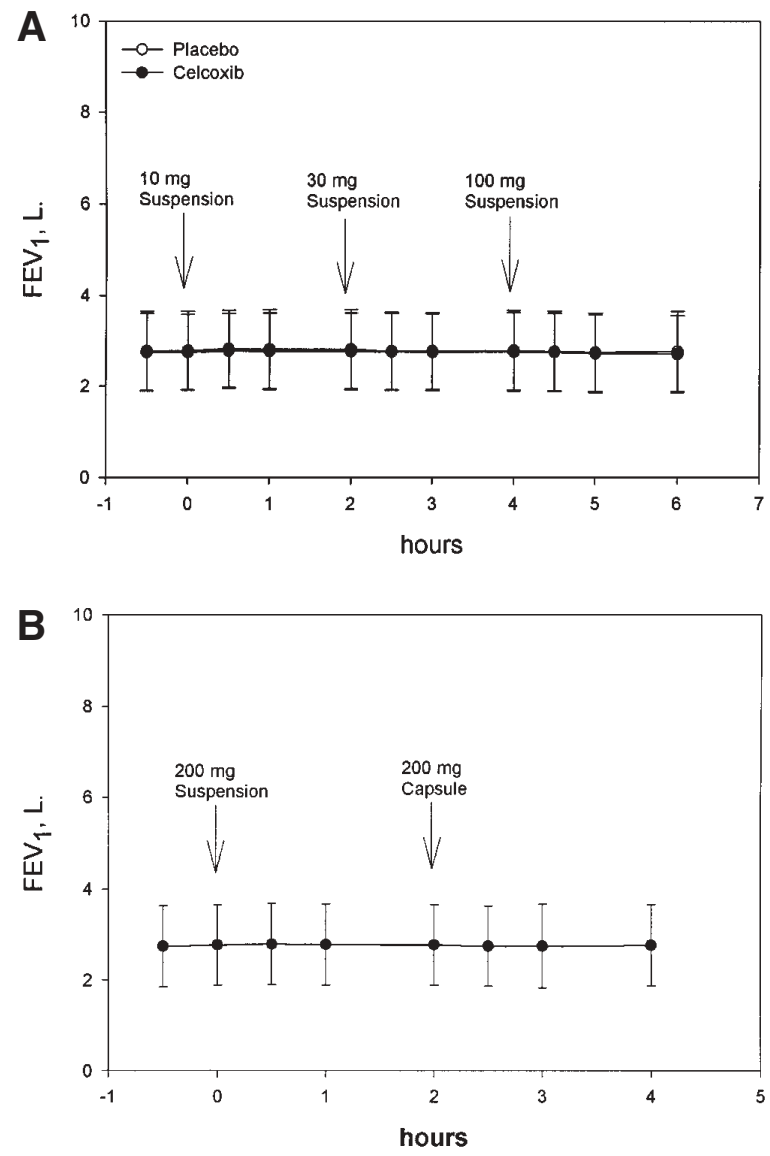

FIG 2. A, Pulmonary function measured as $F E V_{1}$ in liters $(n=33$, mean $\pm \mathrm{SD}$ ) during the cross-over, double-blind, increasing-dose challenge with celecoxib and placebo. Four subjects who were sensitive to very low doses of aspirin entered this protocol after having been subjected to placebo and $5 \mathrm{mg}$ of celecoxib at -2 hours without any reactions. B, Pulmonary function measured as $\mathrm{FEV}_{1}$ in liters ( $\mathrm{n}=33$, mean $\pm \mathrm{SD}$ ) during the open-label challenge with 200-mg celecoxib suspension followed by a $200-\mathrm{mg}$ capsule.

clinical dose, there were no untoward reactions observed from the lower or upper airways, the eyes, the skin, the gastrointestinal system, or any other organ system. Neither was there a change in urinary $\mathrm{LTE}_{4}$ after the exposure to celecoxib. Thus clinical symptoms, pulmonary physiology, and measurements of a sensitive biochemical marker of aspirin intolerance support the hypothesis that the selective COX-2 inhibitor was unable to cause the intolerance reaction otherwise triggered by any conventional NSAID in this particular group of subjects.

The present study is the largest placebo-controlled investigation of the safety of celecoxib in subjects with asthma and aspirin intolerance. The subjects were from 3 different countries and recruited from 3 centers with considerable experience with aspirin intolerance. In addition to a medical history characteristic of AIA, current airway sensitivity to NSAIDs was demonstrated in all subjects by means of aspirin challenge. Collection of urine during a majority of the prestudy aspirin challenges also documented increased urinary LTE $_{4}$ levels in association with 

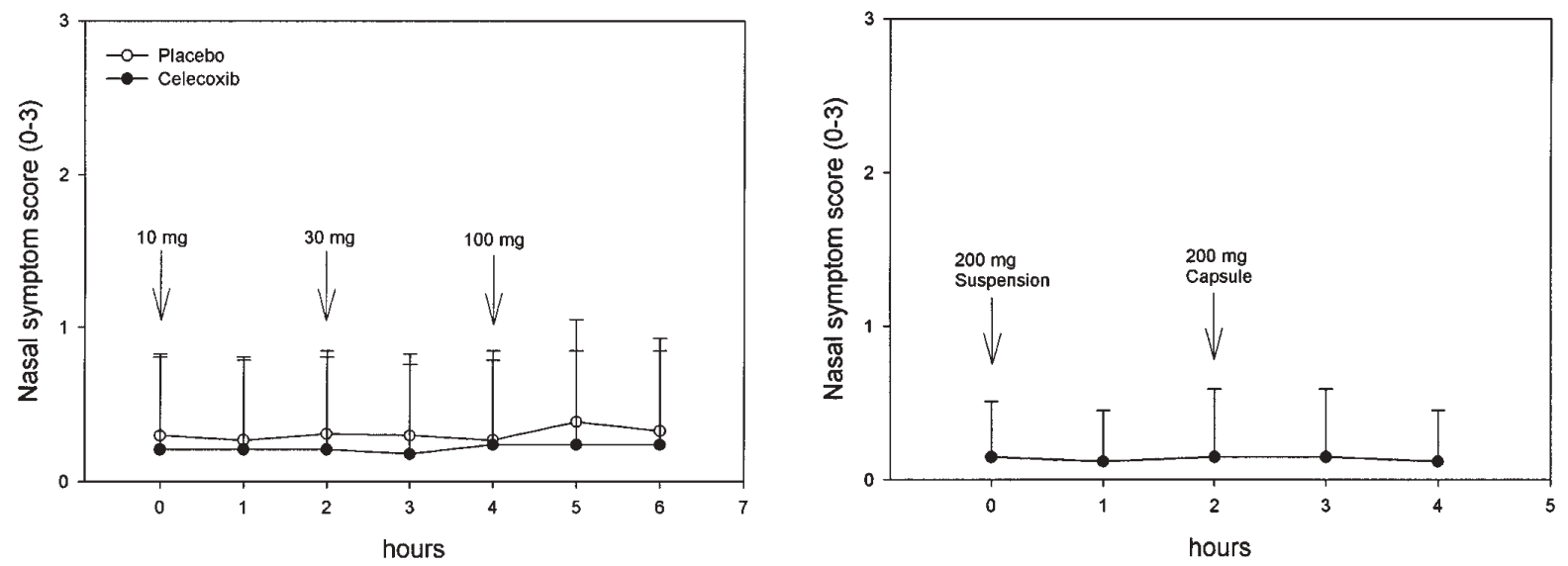

FIG 3. Nasal symptom scores $(n=33$, mean \pm SD) during the double-blind and open-label challenge sessions.

TABLE I. Subject characteristics

\begin{tabular}{|c|c|c|c|c|c|}
\hline Subject no. & Age (y) & Sex & $\mathrm{FEV}_{1}$ (L) & $\mathrm{FEV}_{1}$ ( $\%$ predicted) & Regular drug treatment (explanations below) \\
\hline 1 & 53 & $\mathrm{~F}$ & 2.16 & 84.7 & ICS, LAB, LTRA, SAB \\
\hline 2 & 30 & M & 3.99 & 97.8 & SAB \\
\hline 3 & 69 & $\mathrm{~F}$ & 1.53 & 85.0 & ICS, LAB, SAB \\
\hline 4 & 29 & $\mathrm{~F}$ & 3.01 & 100.3 & ICS, NCS, LAB, LTRA, SAB \\
\hline 5 & 36 & $\mathrm{~F}$ & 2.46 & 89.8 & SAB \\
\hline 6 & 47 & $\mathrm{~F}$ & 2.18 & 82.0 & ICS, NCS, LAB, LTRA, SAB \\
\hline 7 & 56 & $\mathrm{~F}$ & 2.15 & 88.1 & ICS, SAB \\
\hline 8 & 46 & $\mathrm{~F}$ & 2.03 & 75.5 & ICS, LAB, LTRA, SAB \\
\hline 9 & 30 & M & 3.68 & 85.8 & ICS, SAB \\
\hline 10 & 55 & $\mathrm{~F}$ & 2.22 & 87.4 & SAB \\
\hline 11 & 54 & $\mathrm{~F}$ & 2.58 & 90.8 & ICS, LTRA, SAB \\
\hline 12 & 47 & $\mathrm{~F}$ & 2.41 & 82.0 & OS, ICS, NCS, SAB \\
\hline 13 & 50 & M & 2.91 & 80.2 & OS, ICS, LAB, SAB \\
\hline 14 & 33 & M & 4.21 & 94.2 & OS, ICS, LAB, NCS, SAB \\
\hline 15 & 38 & M & 3.20 & 91.4 & ICS, NCS, SAB \\
\hline 16 & 20 & $\mathrm{~F}$ & 3.41 & 95.5 & ICS, DSCG, SAB \\
\hline 17 & 28 & M & 3.42 & 70.8 & OS, ICS, LAB, SAB \\
\hline 18 & 49 & $\mathrm{~F}$ & 1.65 & 71.7 & OS, ICS, LAB, THEO, SAB \\
\hline 19 & 41 & $\mathrm{~F}$ & 2.24 & 75.4 & OS, ICS, LAB, LTRA, SAB \\
\hline 20 & 25 & $\mathrm{~F}$ & 2.81 & 90.6 & ICS, LAB, THEO, SAB \\
\hline 21 & 43 & $\mathrm{~F}$ & 2.02 & 78.6 & ICS, LAB, THEO, SAB \\
\hline 22 & 30 & M & 3.97 & 82.5 & ICS, SAB \\
\hline 23 & 24 & $\mathrm{M}$ & 4.35 & 91.0 & NCS, SAB \\
\hline 24 & 27 & $\mathrm{~F}$ & 3.46 & 95.1 & ICS, NCS, SAB \\
\hline 25 & 70 & $\mathrm{~F}$ & 1.88 & 91.7 & ICS, LTRA, SAB \\
\hline 26 & 50 & $\mathrm{~F}$ & 2.13 & 75.3 & ICS, LAB, SAB \\
\hline 27 & 38 & M & 2.92 & 78.5 & ICS, NCS, LAB, SAB \\
\hline 28 & 43 & M & 3.47 & 84.0 & ICS, NCS, LAB, LTRA, SAB \\
\hline 29 & 61 & M & 2.72 & 73.5 & ICS, NCS, LTRA, SAB \\
\hline 30 & 31 & M & 3.58 & 77.0 & ICS, SAB \\
\hline 31 & 62 & $\mathrm{~F}$ & 1.64 & 71.6 & ICS, NCS, LAB, LTRA, SAB \\
\hline 32 & 66 & $\mathrm{~F}$ & 1.49 & 81.4 & ICS, SAB \\
\hline 33 & 52 & F & 2.24 & 99.1 & ICS, NCS, SAB \\
\hline Mean & 43.4 & $21 \mathrm{~F} / 12 \mathrm{M}$ & 2.73 & 84.8 & \\
\hline Range & $20-70$ & & $1.49-4.35$ & $70.8-100.3$ & \\
\hline
\end{tabular}

ICS, Inhaled corticosteroid; $L A B$, long-acting \-agonist; $L T R A$, leukotriene receptor antagonist; SAB, short-acting \-agonist when needed; NCS, nasal corticosteroid; OS, oral glucocorticosteroid; DSCG, disodium cromoglycate; THEO, theophylline.

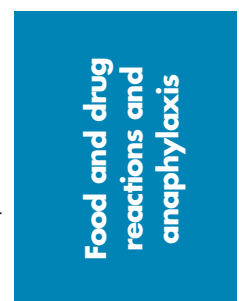

the intolerance reaction (Fig 1). Moreover, the study group included the range of patients normally seen to have AIA. There were those with relatively severe asthma and extreme sensitivity to aspirin (reaction to inges- tion of $40 \mathrm{mg}$ or inhalation of $0.2 \mathrm{mg}$ ) but also a few subjects who displayed symptoms only when given clinically used doses of aspirin ( 250 to $360 \mathrm{mg}$ ). Taken together, the findings in this study support the general conclusion 

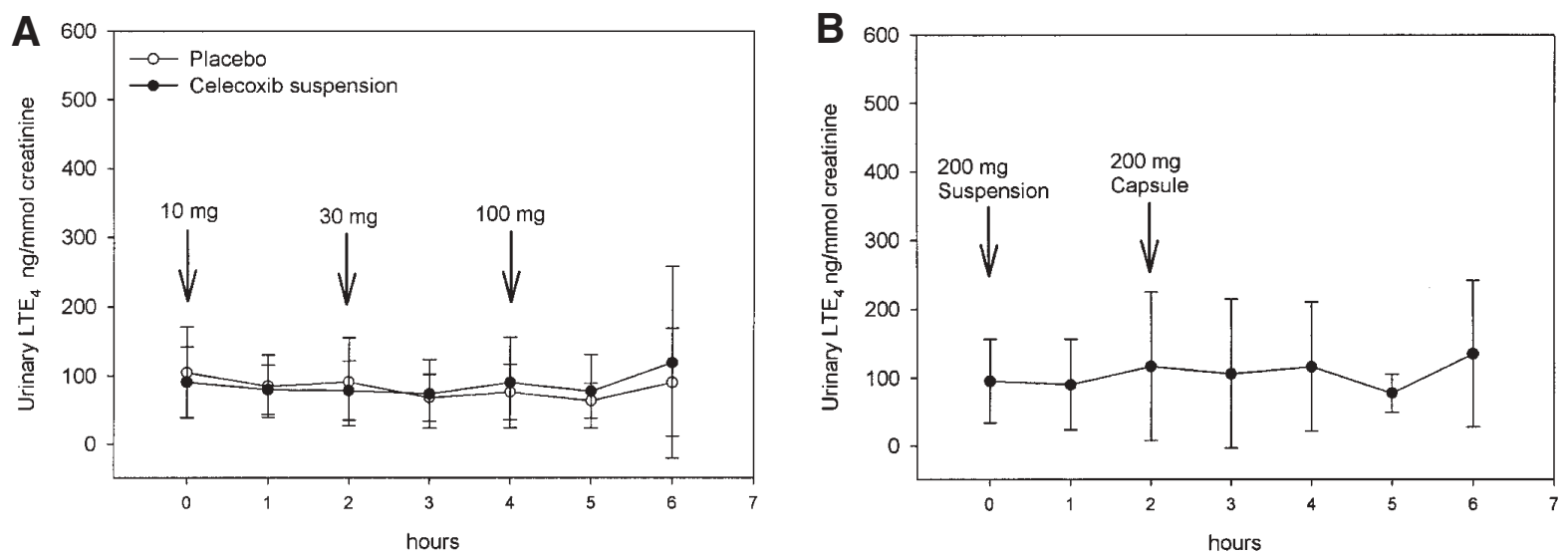

FIG 4. A, Urinary excretion of $\mathrm{LTE}_{4}$ during the double-blind sessions ( $n=33$, mean $\pm S D$ ). The value at any time point after the start of the challenges was not statistically different from baseline (time $=0$ ). B, Urinary excretion of $\mathrm{LTE}_{4}$ during the open-label celecoxib challenge session ( $n=33$, mean $\pm \mathrm{SD}$ ). The value at any time point after the start of the challenges was not statistically different from baseline (time $=0$ ).

TABLE II. Positive responses during screening aspirin challenges

\begin{tabular}{lcc}
\hline & \multicolumn{2}{c}{ Type of challenge } \\
\cline { 2 - 3 } Response & Lysine-aspirin inhalation $(\mathbf{n}=\mathbf{1 6})$ & Oral aspirin challenge $(\mathbf{n}=\mathbf{1 7})$ \\
\hline $\mathrm{FEV}_{1}$ decrease by $\geq 20 \%$ & $\mathrm{n}=10$ & $\mathrm{n}=12$ \\
$\mathrm{FEV}_{1}$ decrease by $\geq 15 \%$ with associated & $\mathrm{n}=6$ & $\mathrm{n}=2$ \\
$\quad \begin{array}{l}\text { nasal congestion, conjunctivitis, dermal flush, } \\
\text { and/or GI symptoms }\end{array}$ & - & $\mathrm{n}=3$ \\
$\begin{array}{l}\mathrm{FEV} \text { decrease by } \geq 15 \% \text { with associated urticaria, } \\
\quad \text { angioedema, and/or hypotension }\end{array}$ & & $38-360 \mathrm{mg}$ \\
\hline \begin{tabular}{l} 
Dose of aspirin at positive reaction (range) \\
\hline
\end{tabular}
\end{tabular}

GI, Gastrointestinal.

*Dosimeter $(\mathrm{n}=10)$

†Concentration in nebulizer $(\mathrm{n}=6)$.

that aspirin-intolerant subjects with asthma tolerate a selective COX-2 inhibitor. Several of the patients in this study have in fact subsequently been prescribed celecox$i b$ or rofecoxib for treatment of lumbago or headaches without adverse reactions.

Rofecoxib is, at least in vitro, even more COX-2 selective than celcoxib. ${ }^{22}$ In our open-label challenge, however, the subjects received twice the normal clinical dose of celecoxib without responding with adverse reactions. As discussed also for other aspects of the clinical use of COX-2 inhibitors, ${ }^{22}$ in vitro differences might thus have little bearing on the effects displayed at the dose ranges experienced in clinical practice.

Three other studies that support the conclusion that subjects with AIA tolerate selective COX-2 inhibitors have recently been published. ${ }^{23-25}$ Yoshida et $\mathrm{al}^{23}$ reported that a single dose of $200 \mathrm{mg}$ of celecoxib was tolerated in 17 aspirin-intolerant subjects with mild asthma whose symptoms were controlled solely with $\square$-agonists. In a full article by Szczeklik et al, ${ }^{24}$ the selective COX-2 inhibitor rofecoxib was found to be tolerated in 12 patients with AIA. As in our study with celecoxib, there was no change in urinary $\mathrm{LTE}_{4}$ levels after exposure to rofecoxib. Finally, Stevenson and Simon ${ }^{25}$ performed double-blind placebo-controlled challenges with rofe- coxib in 60 subjects with established aspirin-induced bronchoconstriction without the occurrence of any respiratory reactions.

Despite these seemingly homogenous findings with COX-2 inhibitors in subjects with AIA, it is premature to recommend indiscriminate use of COX-2 inhibitors in NSAID-intolerant subjects. First, it is established that subjects with isolated skin reactions, such as urticaria, to NSAIDs represent a clinically distinct entity. ${ }^{26}$ This is supported by a recent study of 110 subjects with NSAIDinduced urticaria or angioedema. ${ }^{27}$ In contrast to our present findings and data from others ${ }^{23-25}$ on AIA, it was found that COX-2 preferential (nimesulide or meloxicam) or selective (celecoxib and rofecoxib) drugs elicited cutaneous reactions in a significant proportion (3\%$33 \%$ ) of the patients with established skin reactions to conventional NSAIDs. However, there were no reports of bronchoconstriction. Second, one subject without asthma but with a history of NSAID-induced anaphylactoid reactions did respond also to celecoxib. ${ }^{28}$ Third, although the safety of selective COX-2 inhibitors in acute studies of AIA now would seem to be very well supported, large long-term studies are required before subjects with AIA can be advised to routinely take this new class of drugs. For example, in this tolerance study all patients had asth- 
ma that was well controlled. The effects of celecoxib and other COX-2 inhibitors must be evaluated also in normal practice, when patients might be unstable.

Despite this potential caveat, the investigation nevertheless provides strong support for the conclusion that at least aspirin-induced bronchoconstriction is due to inhibition of COX-1 rather than COX-2. This obviously has considerable mechanistic ramifications and will provide new stimulation of research into the intriguing syndrome of AIA. Should chronic treatment trials corroborate our findings in this tolerance study, patients with AIA will clearly welcome the emergence of a new and safe NSAID to be used for the treatment of pain, fever, and inflammation. For the time being, we suggest that subjects with AIA might use selective COX-2 inhibitors only after first having been exposed to the drug under supervision by a specialist in a clinic with access to standard rescue measures.

We thank Margareta Andersson, Heléne Blomqvist, Margitha Dahl, Ingrid Delin, Gunnel DeForest, Christina Larsson, Brendie Keane, and Lee Morgan for expert technical assistance.

\section{REFERENCES}

1. Szczeklik A, Stevenson DD. Aspirin-induced asthma: advances in pathogenesis and management. J Allergy Clin Immunol 1999;104:5-13.

2. Szczeklik A, Gryglewski RJ, Czemiawska-Mysik G. Relationship of inhibition of prostaglandin biosynthesis by analgesics to asthma attacks in aspirin-sensitive patients. BMJ 1975;1:67-9.

3. Raud J, Dahlén SE, Sydbom A, Lindbom L, Hedqvist P. Enhancement of acute allergic inflammation by indomethacin is reversed by prostaglandin E2: apparent correlation with in vivo modulation of mediator release. Proc Natl Acad Sci U S A 1988;85:2315-9.

4. Hartert TV, Dworski RT, Mellen BG, Oates JA, Murray JJ, Sheller JR. Prostaglandin E2 decreases allergen-stimulated release of prostaglandin D2 in airways of subjects with asthma. Am J Respir Crit Care Med 2000;162:637-40.

5. Smith WL, Langenbach R. Why there are two cyclooxygenase isozymes. J Clin Invest 2001;107:1491-5.

6. Scott LJ, Lamb HM. Rofecoxib. Drugs 1999;58:499-507.

7. Clemett D, Goa KL. Celecoxib: a review of its use in osteoarthritis, rheumatoid arthritis and acute pain. Drugs 2000;59:957-80.

8. Silverstein FE, Faich G, Goldstein JL, Simon LS, Pincus T, Whelton A, et al. Gastrointestinal toxicity with celecoxib vs non-steroidal antiinflammatory drugs for osteoarthritis and rheumatoid arthritis: the CLASS study, a randomized controlled trial. JAMA 2000;284:1247-55.

9. Bjarnason I, Rainsford KD. COX-2 inhibitors and the gastrointestinal tract [letter]. Gut 2001;48:451.

10. Fries JF. Gastrointestinal toxicity of nonsteroidal antiinflammatory drugs. N Engl J Med 1999;341:1397-9.
11. Vane JR, Bakhle YS, Botting RM. Cyclooxygenases 1 and 2. Annu Rev Pharmacol Toxicol 1998;38:97-120.

12. Dahlén B, Boréus LO, Anderson P, Andersson R, Zetterström O. Plasma acetylsalicylic acid and salicylic acid levels during aspirin provocations in aspirin-sensitive subjects. Allergy 1994;49:43-9.

13. Andri L, Senna G, Betteli C, Givanni S, Scaricabarozzi I, Mezzelani P, et al. Tolerability of nimesulide in aspirin-sensitive patients. Ann Allergy 1994;72:29-32.

14. Bavbek S, Celik G, Ediger D, Mungan D, Demirel YS, Misirligil Z. The use of nimesulide in patients with acetylsalicylic acid and nonsteroidal anti-inflammatory drug intolerance. J Asthma 1999;36:657-63.

15. Kosnik M, Music E, Matjaz F, Suskovic S. Relative safety of meloxicam in NSAID-intolerant patients. Allergy 1998;53:1231-3.

16. Dahlén B, Szczeklik A, Murray JJ. Celecoxib in patients with asthma and aspirin intolerance [letter]. N Engl J Med 2001;344:142.

17. Christie PE, Tagari P, Ford-Hutchinson AW, Charlesson S, Chee P, Arm JP, et al. Urinary leukotriene E4 concentrations increase after ASA challenge in ASA-sensitive asthmatic subjects. Am Rev Respir Dis 1991;143:1025-9.

18. Kumlin M, Dahlén B, Björck T, Zetterström O, Granström E, Dahlén SE. Urinary excretion of leukotriene E4 and 11-dehydro-thromboxane B2 in response to bronchial provocations with allergen, aspirin, leukotriene D4, and histamine in asthmatics. Am Rev Respir Dis 1992;146:96-103.

19. Dahlén B, Kumlin M, Margolskee DJ, Larsson C, Blomqvist H, Williams VC, et al. The leukotriene-receptor antagonist MK-0679 blocks airway obstruction induced by bronchial provocation with lysine-aspirin in aspirin-sensitive asthmatics. Eur Respir J 1993;6:1018-26.

20. Nizankowska E, Bestynska-Krypel A, Cmiel A, Szczeklik A. Oral and bronchial provocation tests with aspirin for diagnosis of aspirin-induced asthma. Eur Respir J 2000;15:863-9.

21. Kumlin M, Stensvad F, Larsson L, Dahlén B, Dahlén S-E. Validation and application of a new simple strategy for measurements of leukotriene E4 in human urine. Clin Exp Allergy 1995;25:467-79.

22. FitzGerald AG, Patrono C. The coxibs, selective inhibitors of cyclooxygenase-2. N Engl J Med 2001;345:433-42.

23. Yoshida S, Ischizaki Y, Onuma K, Shoji T, Nakagawa H, Amayasu H. Selective cyclo-oxygenase 2 inhibitor in patients with aspirin-induced asthma. J Allergy Clin Immunol 2000;106:1201-2

24. Szczeklik A, Nizankowska E, Bochenek G, Nagraba K, Mejza F, Swierczynska M. Safety of a specific COX-2 inhibitor in aspirin-induced asthma. Clin Exp Allergy 2001;31:219-25.

25. Stevenson DD, Simon RA. Lack of cross-reactivity between rofecoxib and aspirin in aspirin-sensitive patients with asthma. J Allergy Clin Immunol 2001;108:47-51.

26. Stevenson DD, Simon RA. Aspirin sensitivity: respiratory and cutaneous manifestations. In: Middleton E, Reed CE, Ellis EF, Adkinson NF, Younginger JW, eds. Allergy: principles and practice. St Louis: Mosby; 1988. p. 1537-58.

27. Sfinches Borges M, Capriles-Hulett A, Caballero-Fonsenca F, Pérez CR Tolerability of new COX-2 inhibitors in NSAID-sensitive patients with cutaneous reactions. Ann Allergy Asthma Immunol 2001;87:201-4.

28. Schellenberg RR, Isserow SH. Anaphylactoid reaction to a cyclooxygenase-2 inhibitor in a patient who had a reaction to a cyclooxygenase-1 inhibitor. N Engl J Med 2001;345:1856. 